Florida International University FIU Digital Commons

7-25-1997

\title{
A phenomenological study of self-disclosure of male's HIV seropositivity to another person
}

Elaine A. DiVeronica

Florida International University

DOI: $10.25148 /$ etd.FI15101202

Follow this and additional works at: https://digitalcommons.fiu.edu/etd

Part of the Nursing Commons

\section{Recommended Citation}

DiVeronica, Elaine A., "A phenomenological study of self-disclosure of male's HIV seropositivity to another person" (1997). FIU Electronic Theses and Dissertations. 3064.

https://digitalcommons.fiu.edu/etd/3064 
FLORIDA INTERNATIONAL UNIVERSITY

Miami, Florida

\title{
A PHENOMENOLOGICAL STUDY OF SELF-DISCLOSURE OF MALE'S HIV SEROPOSITIVITY TO ANOTHER PERSON
}

A thesis submitted in partial satisfaction of the requirements for the degree of MASTER OF SCIENCE

\author{
IN \\ NURSING \\ by \\ Elaine A. DiVeronica
}


To: Linda A. Simunek

School of Nursing

This thesis, written by Elaine A. DiVeronica, and entitled A PHENOMENOLOGICAL STUDY OF SELF-DISCLOSURE OF MALE'S HIV SEROPOSITIVITY TO

ANOTHER PERSON, having been approved in respect to style and intellectual content, is referred to you for judgement.

We have read this thesis and recommend that it be approved.

Tomas Madayag

Ralph Liporace

Sandra Lobar, Major Professor

Date of Defense: July 25, 1997

The thesis of Elaine A. DiVeronica is approved.

Dean Linda A. Simunek

School of Nursing

Dr. Richard L. Campbell

Dean of Graduate Studies

Florida International University, 1997 


\section{DEDICATION}

I dedicate this Master's thesis to my best friend and husband, Nicholas. 


\section{ACKNOWLEDGMENTS}

I wish to thank the members of my committee, Dr. Tomas Madayag, Dr. Ralph Liporace, and Dr. Sandra Lobar, for their guidance and support. I also would like to express my deepest gratitude to the staff of Wardzala, Liporace \& Associates, for allowing me the opportunity to conduct this study at their office. I would like to thank the participants of this study who were willing to share a piece of themselves with me, and special thanks to those men who did not survive to see this study completed. I would like to thank Dr. Larry Wardzala, my mentor, for his support; and Dr. Ralph Liporace, my friend, for his encouragement.

A special thanks to my major professor, Dr. Sandra Lobar, for her support, confidence, and unerring patience in the completion of this study. 


\title{
A PHENOMENOLOGICAL STUDY OF SELF-DISCLOSURE OF MALE'S HIV SEROPOSITIVITY TO ANOTHER PERSON
}

by

\author{
Elaine A. DiVeronica \\ Florida International University, 1997 \\ Miami, Florida \\ Professor Sandra Lobar, Major Professor
}

This phenomenological study described the fundamental structure of what it was like for men to tell someone of their HIV-positive status. Nineteen men participated in interviews to describe their experiences of self-disclosing their HIV-positive status to lovers, families, and friends. The data were analyzed first by using the phenomenological approach of Colaizzi. Data were then further analyzed using an approach by Van Manen, in which the lifeworld existentials of spatiality, temporality, and relationality provided an even clearer understanding of the phenomenon. The findings from both analyses revealed that the participants felt emotions such as rejection, denial, and lost tomorrows; as well as, advice on who, how and when to tell. These emotions developed into four themes: Price of Honesty, Telling, Realization, and Isolation. Knowledge of these thoughts and emotions may help nurses to formulate therapeutic interventions in which self-disclosure issues are addressed in other individuals. 


\section{TABLE OF CONTENTS}

CHAPTER

PAGE

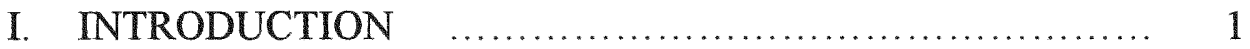

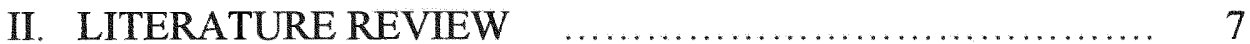

HIV/AIDS Self-Disclosure Studies $\ldots \ldots \ldots \ldots \ldots \ldots \ldots \ldots \ldots$

General Self-Disclosure Studies $\quad \ldots \ldots \ldots \ldots \ldots \ldots \ldots \ldots \ldots . \ldots \ldots \ldots . \ldots \ldots$

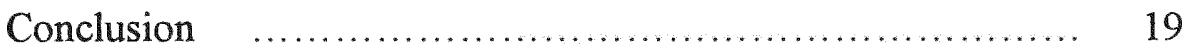

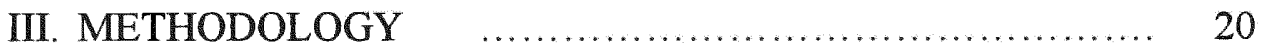

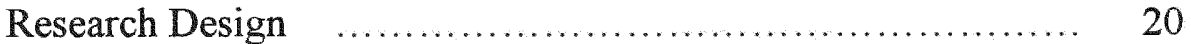

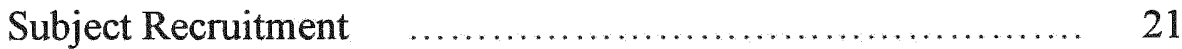

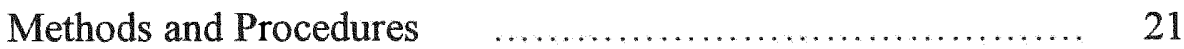

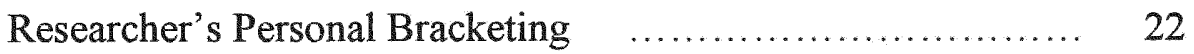

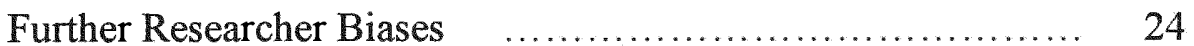

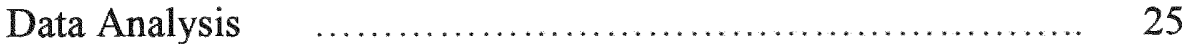

Phenomenological Reliability and Validity $\ldots . . . . . . . . . \ldots .29$

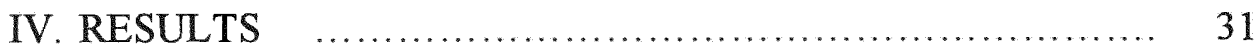

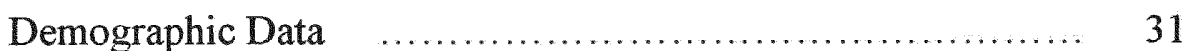

Data Analysis Using Colaizzi's Approach $\quad$................ 31

Fundamental Structure of Self-Disclosure $\quad \ldots \ldots \ldots \ldots \ldots . . . \ldots .43$

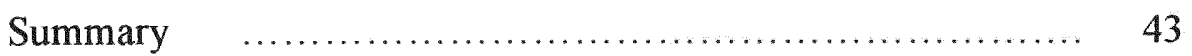

Data Analysis Using Van Manen's Approach $\quad . . . . . . . . . . . . .44$

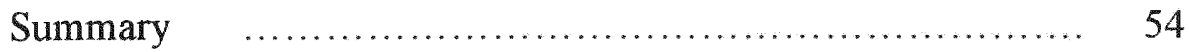

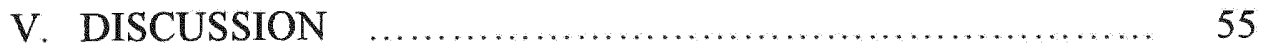

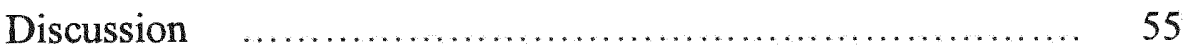

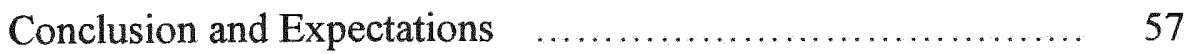

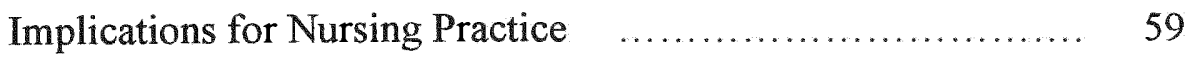

Recommendations for Further Research $\quad \ldots \ldots \ldots . . . . . . . . . . .59$

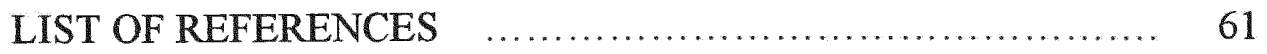

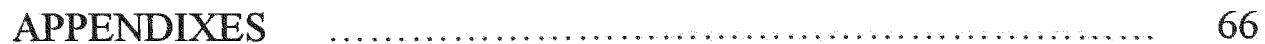




\section{CHAPTER 1}

\section{Introduction}

\section{Background and Significance of the Problem}

Until recently, having the human immunodeficiency virus (HIV) was an automatic death sentence. Societal beliefs have caused individuals to surmise that admission of positive HIV status automatically suggested one's participation in socially unacceptable practices, such as intravenous drug use, homosexual intercourse, multiple sexual partners, or unusual sexual practices (Fineberg, 1988; Sobo, 1995). In reality, even though HIV can be contracted through sexual activity, it may also be contracted by receiving infected blood or blood products, or transplacentally (Fanning, 1997).

In the past, by the time the HIV antibody was detected, a diagnosis of AIDS (acquired immunodeficiency syndrome) and death were not far behind. There was little time for these individuals to prepare for self-disclosing their HIV status. Today, with continuing medical breakthroughs in this area, HIV-positive individuals are living longer and healthier lives; self-disclosure issues, such as who and when to tell, have become one of their major concerns (Doll, Harrison, Frey, McKirnan, Bartholow, Douglas, Jr., Joy, Bolan, \& Doetsch, 1994).

The feelings and behaviors associated with HIV self-disclosure need to continue to be examined and described so that nurses and other health care providers can become further informed and offer assistance to those currently infected and to those who become infected. "Our world has been made a different place by the human 
immunodeficiency virus. More profoundly, our society is being shaped by our response to the epidemic" (Fineberg, 1988, p. 134).

\section{General Statement of Problem Area}

Limandri (1989) stated:

When individuals perceive that they have a condition that the general society disapproves of or views with disgust, they attempt to conceal their condition as much as possible .... It is reasonable to assume that individuals with stigmatizing conditions would prefer not to disclose their condition to others. Even though the condition has relevance to individuals' physical and psychosocial health states, they may choose to avoid health care to avoid disclosure (p. 69).

Self-disclosure may be defined as "verbal behavior through which individuals truthfully, sincerely and intentionally communicate novel, ordinarily private information about themselves to one or more addressees" (Fisher, 1984, p. 278). "Self-disclosure involves decisions about whether to reveal one's thoughts, feelings, or past experiences to another person, at what level of intimacy to reveal personal information, and the appropriate time, place, and target person for disclosure" (Derlega, 1988, p. 29).

To further the understanding of the self-disclosure process, Derlega, Metts, Petronio \& Margulis (1993) discussed some of both the harmful and beneficial effects of selfdisclosure. Harmful effects included: (a) feelings of shame and guilt by the event; (b) great expenditures of energy and effort, resulting in poor physical and psychological health; (c) creation of doubts about one's self-worth, raised concerns about the future, and lowered confidence to deal with everyday problems; (d) attention focused on real or 
imagined weaknesses or faults; (e) anticipation of self-disclosure magnified negative effects; (f) self-disclosure of negative feelings generated discomfort in the discloser and caused the listener to feel upset and embarrassed; and (g) if negative feelings were aroused in the listener, the discloser experienced rejection. However, these authors also noted several beneficial aspects of self-disclosure: (a) relief of feelings of guilt or shame; (b) helped the individuals see themselves in a more positive way; (c) immediately reduced the physiological work of secrecy; (d) helped the individual to understand and find meaning in the event, and ended the obsession with unwanted feelings; (e) helped the individual to feel accepted, loved, and valued despite the event; (f) information, advice and guidance were provided to assist in coping with the event; and (g) other people became available to offer encouragement (Derlega et al., 1993).

Flaskerud \& Ungvarski (1995) felt that, with reference to HIV self-disclosure, individuals who had considered their sexuality to be a private matter were now subject to public exposure and possible rejection by family and friends. These individuals felt they may be abandoned by those who had accepted their sexuality but were afraid of HIV transmission. These authors felt that "at a time when people most need social support, comfort, compassion, and closeness, they might be left alone and isolated" (p. 317).

The clinical management of HIV/AIDS disease-related information has been adequately addressed in the research by health care professionals; however, few qualitative nursing studies have considered the devastating emotional impact of disclosing one's positive HIV status to another person. Fanning (1997) suggested that physicians and other health care providers need to be understanding of this process. 


\section{Purpose of the Study}

The purpose of this research was to understand the experience of revealing HIVseropositivity to another person (i.e. partner, friend, family member, etc.) for an HIVpositive male, from a phenomenological perspective of inquiry. This inquiry focused on exploring and interpreting the males' lived experiences as narrated by them. As nurses become more clinically proficient in HIV/AIDS care, they also need to become more aware of the psychosocial concerns of their patients. By interviewing HIV-positive males about their experiences of self-disclosure, a body of knowledge will accumulate that will contribute to a better understanding of the actual lived experience of self-disclosing HIV-seropositivity to another person.

\section{$\underline{\text { Research Problem }}$}

Few qualitative studies were found in the literature that addressed the thoughts, feelings, and behaviors involved in revealing to another person a particularly intimate, yet significant fact, such as HIV-seropositivity. Perhaps a clearer picture can be formulated when nurses better understand the emotions that are involved in a disclosure of this magnitude and its resultant effects on the discloser.

\section{Research Question}

The research question generated for this study was "What was it like to tell another person that you were HIV-positive?" Participants were asked to share their feelings, thoughts and perceptions of a situation(s) in which they told another person (lover, friend, family member, health professional) of their positive HIV status. Broad open- 
ended clarifying questions were asked throughout the interview to obtain the most thorough picture of the self-disclosure process.

\section{Significance of the Study}

Research is vitally needed which clarifies the significance of HIV/AIDS selfdisclosure. Since the advent of AIDS, nurses and other health care professionals have had to re-evaluate their own belief systems. For some, the transition has been made; but for others, the struggle with the morality issues of this disease may still remain. Through qualitative research, nurses may be able to "... unveil aspects of care and treatment that are more appropriate and effective for the prevention of the disease, diagnosis, and treatment" (p. 22) and better enable medical practitioners to understand, empathize, and counsel more effectively (Mullins, 1996).

The significance of this study lies in the overall need for a phenomenological examination of the self-disclosure process as HIV/AIDS becomes a manageable chronic disease. The ultimate aim of phenomenological inquiry is to facilitate the process of becoming more fully human. The findings from this research speak to the essence of what it is like to be HIV-positive and the lived experience of disclosing that information to another person.

\section{Researcher Assumptions and Biases}

In performing phenomenological research, the researcher's assumptions, biases, intuitions, and perceptions must be identified by a process called bracketing. The researcher needed to overcome private feelings, preferences or expectations that might prevent coming to terms with an experience as it is being lived. This process required the 
researcher to set aside any previous personal beliefs or judgments about the phenomenon under investigation to prevent this information from interfering with recovering the purest description of the phenomenon (Streubert \& Carpenter, 1995).

Munhall (1994) states “. . the aim of bracketing is to set aside our own beliefs for a period of time so that we can 'hear' and 'see', as undisturbed as is possible by our own knowing. This unknowing allows for openness and also allows us to converse with our participants without attempting to validate our own presuppositions and beliefs" (p. 62). Therefore, by bracketing personal knowledge and bias, the researcher attempted to experience and understand the phenomenon, as if looking at it for the first time.

\section{Limitations}

The reader is cautioned regarding making far-reaching generalizations. The males in this study may not represent the larger world of HIV-positive males and meanings identified may not be generalizable to represent all males with experiences of the phenomenon of HIV-positive self-disclosure. The individuals in this study were all recruited from an office of private HIV-specialty physicians and were professionally known to the researcher. During the recruiting process, the researcher briefly explained the study, and all individuals that were approached readily agreed to participate in the study. 


\section{CHAPTER 2}

\section{Review of Literature}

A review of the literature revealed that a number of studies have been done on the subject of HIV serostatus self-disclosure. However, few studies still address this subject as it relates qualitatively to the actual phenomenon of self-disclosing HIV-seropositivity to another person. The following literature review encompasses a selection of research studies as they relate to HIV/AIDS self-disclosure studies and general self-disclosure studies.

\section{HIV/AIDS Self-Disclosure Studies}

Presented below are studies that discuss self-disclosure as it relates to those individuals who are HIV-positive. Included are studies conducted on both homosexual and heterosexual men, as well as women.

Marks, Richardson, \& Maldonado (1991) performed a quantitative study to determine if a relationship existed between prevalence of HIV nondisclosure and unsafe sexual practices. The study consisted of 138 HIV-positive men recruited from a predominately Hispanic area of Los Angeles, $91 \%$ of whom identified themselves as either homosexual or bisexual. Each participant completed a self-administered questionnaire in which sexual activity and disclosure were measured with a matrix checklist. Participants were instructed to check the activities that had occurred with each sexual partner and to indicate whether they had revealed their HIV infection before the activity, and whether the sexual partner was known to be HIV infected. Results $(p<.01)$ indicated that as the number of sexual partners increased, the likelihood of disclosure decreased. 
Marks, Bundek. Richardson, Ruiz, Maldonado, \& Mason (1992) conducted a quantitative study which examined mens' self-disclosure of HIV infection to other individuals. The sample consisted of $101 \mathrm{HIV}$-positive Hispanic men who completed self-administered questionnaires. The findings demonstrated that the subjects tended to tell of their HIV-positive status to significant others rather than less significant others; that gay and bisexual subjects were more inclined to reveal their HIV-positive status to other known HIV-positive individuals who were also aware of their sexual orientations; and that disclosure to significant and less significant others increased with severity of disease, regardless of the amount of time since testing HIV-positive. The authors also discovered that essentially no subjects chose to reveal their HIV-positive status to family members who were not already aware of their sexual orientation. The authors noted that their study could have been culturally biased and suggested further cross-cultural studies.

Schnell, Higgins, Wilson, Goldbaum, Cohn, \& Wolitski (1992) performed a quantitative study to determine mens' disclosure of HIV test results to male primary sex partners and to note disruption of relationships between partners. The participants, who consisted of 1,684 men, were asked to complete a standardized self-administered questionnaire every six months during the time period of 1987 to 1990 . The authors reported after the initial visit that " $89 \%$ of both seronegative and seropositive men disclosed the results to their main sex partner" (p. 1675). At the first six month return visit, it was found that the number of relationships that remained strong was slightly higher for HIV-seropositive men and for those men who tested HIV-negative; those that did not inform their main sex partner were more likely to be single. One limitation of this 
study involved the number of initial respondents ( $53 \%$ of seronegative and $66 \%$ of seropositive) who did not return for the first six month visit. Also, it was not stated if the participants were asked to complete the same questionnaire on the first six month visit as they had on the initial visit. An important consideration cited was that health care providers involved in HIV care need to become more knowledgeable regarding their client's concerns about the impact of self-disclosure of HIV serostatus on primary relationships.

Doll, Harrison, Frey, McKirnan, Bartholow, Douglas, Jr., Joy, Bolan, \& Doetsch (1994) analyzed data from a multisite study of 1,063 gay or bisexual men to evaluate factors predicting failure to disclose HIV risk behaviors to medical professionals and the extent of such failure. Detailed study interviews were conducted and each participant completed a self-administered questionnaire. Findings showed that, of the men in this sample who engaged in high-risk sexual behavior, a significant percentage failed to disclose their HIV risk at initial health care screenings. From this study, it was determined that one's expectation of disapproval from health care providers may actively contribute to a failure to disclose risk behaviors, therefore, one may not receive important risk-reduction information. The authors stated "As the number of persons with AIDS and HIV infection increases, the need, and the pressure, for verbal disclosure of HIV risk behaviors and HIV antibody status to both health care providers and sex partners will increase" (p. 128). The authors felt that perhaps health care providers are too cautious about discussing HIV-related issues and may experience difficulty with this very sensitive issue in a medical setting. They also felt that additional research, as well as the 
development of intervention programs, are needed to assist those who are disclosing and receiving sensitive information.

Perry, Card, Moffatt, Ashman, Fishman, \& Jacobsberg (1994) examined voluntary self-disclosure of HIV infection to any past or present sexual partner after repeated counseling. Data were examined for 129 HIV-positive men and women who had completed a risk behavior questionnaire and who had been followed for at least six months. The authors found that even after multiple individual counseling sessions and at least six months to inform others of HIV infection, rates of self-disclosure to sex partners were relatively low. In exploring for variables associated with nondisclosure for both men and women, it was found that those HIV-positive subjects less likely to inform their sex partners had lower anticipated social support, no spouse or live-in partner, and were less comfortable with their sexuality. These findings concluded that disclosing one's HIV-positive infection to a sex partner may be even more difficult among those who feel vulnerable to rejection and who have not established a somewhat permanent relationship with this partner. The authors acknowledged that caution be used when applying their results to other HIV populations. Generally, it was concluded that disclosure of HIV infection did not ensure a reduction in HIV-risk behaviors. Compared to this study's relatively high rates of nondisclosure, it was found that there are still relatively low rates of current unsafe sex practices.

Mansergh, Marks, \& Simoni (1995) conducted a quantitative study to determine men's self-disclosure of their HIV-positive status to other individuals and if there was a parallel with the length of time since testing HIV-positive. The study also looked at some 
of the consequences of self-disclosure. The authors discovered that, of the men who were recently diagnosed HIV-positive, a large percentage had disclosed their HIV-positive status to intimate lovers and friends. A lesser amount had informed their mothers, brothers, or sisters, and even less had disclosed to their fathers. Overall, this study showed that self-disclosure rates did increase with time since HIV diagnosis and suggested mostly favorable outcomes for those individuals who had disclosed their HIV status.

Simoni, Mason, Marks, Ruiz, Reed, \& Richardson (1995) carried out a quantitative study to determine 65 womens' rates of self-disclosure of their HIV-positive status to friends, lovers, and family members; possible explanations for disclosure and nondisclosure; and responses received from the disclosures. The authors found the overall model to be highly significant $(\mathrm{p}<.001)$. Findings revealed the highest rates of self-disclosure were to lovers and friends. The participants cited ethical responsibility and concerns for their lover's health as reasons for their self-disclosures. With regards to reactions to self-disclosure, the following trends appeared:

Mothers, fathers, and friends frequently reacted by providing emotional support and rarely responded by becoming angry or withdrawing. Although lovers appeared to be as frequently emotionally supportive as other targets, the data suggest that they were more likely to become angry and withdraw on learning of the respondent's HIV infection. In fact, $20 \%$ of the lovers reacted to a disclosure by leaving the respondent, suggesting that some respondents' fear of being rejected may be accurate (p. 476). 
The authors admitted that their limited sample size made it difficult to assess ethnic differences in reasons for disclosure and nondisclosure. Also, in addition, their study did not directly assess acculturation or cultural values.

Sobo (1995) performed a qualitative study, using an ethnographic approach, in which a group of four HIV-positive individuals discussed if, when, and how they had disclosed their HIV status to sexual partners. The findings presented were based on an initial focus group consisting of four individuals, three women and one man. The author found that the participants felt that long-term sexual partners needed to be told; however, using safe sex measures negated the need to disclose their HIV-seropositivity with casual sex partners. The participants stated that they knew many HIV-negative individuals who felt they would not get HIV and, therefore, did not practice safe sex. Participants decided if and when to tell by relaying small bits of information about themselves, testing for signs of trust from the prospective disclosee. It was felt that even though self-disclosure could alleviate some of the stress, the fear of rejection was always present. The author noted that individuals were reluctant to pursue self-disclosure help from the medical community due to prior negative experiences related to their HIV diagnosis. The author supports the need for further research in the area of HIV-positive self-disclosure. Limitations of the study include the small sample size (four) and the rurality of the area (southern New Mexico).

Stempel, Moulton, \& Moss (1995) followed 93 subjects from the San Francisco General Hospital Cohort for one year after notifying them of their HIV antibody test results for purposes of examining self-disclosure, reactions, and concerns regarding self- 
disclosure. The authors surmised that self-disclosure to sexual partners may bring about changes in sexual behavior and may motivate earlier interventions by health care providers. The group, consisting of 93 subjects, completed self-administered questionnaires two weeks prior to notification of their HIV antibody test results. At the same time, the subjects were also asked to whom they intended to disclose their HIV antibody test results. Two weeks, three months, six months, and twelve months following notification of their HIV antibody test results, the subjects completed mailed questionnaires indicating whether they had actually told the results of their HIV antibody test results to any other individuals. When a subject had told, they were asked to rate the individual's reaction as "favorable" or "unfavorable". Results indicated that at a period of 12 months after initial notification, subjects were more likely to disclose their HIV antibody test results to all categories of people than they had anticipated two weeks prior to notification. Closest friends, gay and non-gay, were more than twice as likely to be told test results than were family members. Family members, lovers, new sexual partners, and co-workers were most likely to respond unfavorably. Relatively few unfavorable reactions were seen among friends and health professionals, with the exception of unfavorable responses received from dentists. The authors stated "The pattern of test results disclosure may reflect both the distinctive social structure of a gay community and the special nature of information related to sexual activity" (p. 122). Loss of job, insurance, income, and housing were the most frequently cited fears about selfdisclosure. The researchers felt their findings imply that pre- and post-test counseling sessions should include a discussion of self-disclosure of test results. 
Moneyham, Seals, Demi, Sowell, Cohen, \& Guillory (1996) explored issues of selfdisclosure for women infected with HIV using qualitative focus groups. The sample included 19 women who participated in one of four group sessions. The groups were led by an experienced moderator who used a semi-structured interview guide that consisted of open-ended questions about the experience of living with HIV. To address selfdisclosure issues, the participants were asked to describe their experiences of sharing their HIV status with others. Participants uniformly expressed concern about disclosing their HIV status because they anticipated and feared negative responses from others. The descriptions of their experiences in deciding to disclose revealed an evaluative process whereby the risks and benefits of self-disclosure were analyzed, and speculations were made about how the recipient of disclosure would respond. One concern regarding selfdisclosure, as stated by the participants, was fear of discrimination, especially when the disclosure involved people that the participants perceived to have power over some aspect of their lives. Another concern was that the recipient of disclosure could not be trusted to keep confidence. Loss of control of confidentiality represented potential exposure to discrimination. Concerns about confidentiality often kept participants from using resources and services they needed. Of particular concern was being seen using HIV services at places like health clinics. Self-disclosure concerns varied somewhat according to the situation and persons involved. The debate over self-disclosing to health care professionals ran from the positive, such as enhancing the health care providers' ability to give appropriate care; to the negative, such as discrimination, or protection of HIV transmission to the health care professional. Participants expressed unwillingness to 
disclose to sex partners because of their inability to predict how the partner would react. The authors felt that additional research is needed to further our understanding of the process of self-disclosure and the factors that may influence this process, and to provide a basis for developing supportive interventions.

Hoff, Stall, Paul, Acree, Daigle, Phillips, Kegeles, Jinich, Ekstrand, \& Coates (1997) conducted a quantitative study which made comparisons between "concordant" relationships, (i.e., HIV+ respondent/HIV+ partner; HIV- respondent/HIV-partner); and "discordant" relationships, (i.e., respondents whose partner's HIV status was different from their own). The sample consisted of 785 self-identified gay or bisexual men. Men in concordant relationships reported significantly higher rates of unprotected anal intercourse than men in discordant relationships. Men in concordant relationships were more likely than those in discordant relationships to engage in unprotected anal intercourse with their primary partners. Men in mutually monogamous HIV-negative concordant relationships are not at high risk for transmission if they only have sex with each other. The authors suggest future research regarding safe sexual practices within gay male couples.

Katz (1997) used a qualitative approach to explore HIV-positive individuals and their self-disclosure experiences to family members. A convenience sample of ten HIVinfected individuals (nine men and one woman), were asked to participate in semistructured interviews. Findings concluded that some people chose to inform friends and family soon after receiving their HIV-positive test results; they recognized that they needed support and reached out to those close to them for that support. Others needed 
time and space to come to terms with the new reality. They felt they needed a period of personal adjustment before disclosing to others. And others avoided telling their family fearing abandonment. The findings of this study suggested that:

Family members generally overcome the initial shock and pain and begin to provide the infected individual with support and love. While disclosure must be made by the infected individual at a time and place of their own choosing, they can be encouraged to do so sooner rather than later (p. 142).

The author noted that nurses must provide support for HIV-positive individuals who are considering self-disclosure of their HIV status. The nurse may be able to role play the anticipated responses of certain family members; or it may be helpful for the nurse to be present at the time of the self-disclosure to provide needed support and to answer questions. The nurse may also be able to meet with the family members individually or in a group to discuss their fears and concerns.

\section{General Self-Disclosure Studies}

The researcher also investigated studies that involved the self-disclosure process as it relates to other stigmatizing conditions. Studies were found that addressed the issues of genital herpes, domestic violence and cystic fibrosis.

Inhorn (1986) studied the results of two months of field work among a group of American adults of heterogeneous backgrounds and origins, who were brought together because of their status as genital herpes patients. Eight individuals (four men and four women) agreed to be interviewed. Additionally, three sexually active adults (two women and one man), who did not have genital herpes, were interviewed to elicit representative 
attitudes toward this disease from the general sector of the heterosexual population. The issue of honesty was raised by all individuals interviewed and appeared to be a major self-disclosure dilemma faced by genital herpes patients. According to informants, the reason self-disclosure to intimates is so difficult is because of an overwhelming fear of rejection. Several informants admitted that they avoided intimate relationships because of their fear of potential rejection. Of the six individuals with genital herpes who had attempted to have post-herpes sexual relationships, only two could cite definite cases of rejection because of the disease. Of the three individuals interviewed who did not have genital herpes, two of them had already engaged in sexual relationships with partners whom they knew had herpes. The author stated that:

Interviews with eight adults, all affected by genital herpes, reveal how fear of disclosure, and subsequent rejection, plays a powerful role in the daily lives of these individuals. Deciding whether or not and how to tell friends, families, acquaintances, strangers, and worst of all, potential lovers about one's 'secret stigma' proves to be a continuous conundrum for most (p. 62).

Limandri (1989) performed a qualitative study to identify components of selfdisclosure in those individuals affected by stigmatizing conditions. Using grounded theory, Limandri interviewed 29 individuals (13 males and 16 females) with conditions such as domestic violence, HIV-seropositivity or AIDS, or genital herpes. Data were analyzed using constant comparative methodology. Limandri identified five steps involved in the stigmatization self-disclosure process. These steps are the following: 
(a) The person initially comes to the realization that they are affected. This time may consist of alternating between denial and self-confrontation. (b) As the person begins to understand their condition, a point of self-recognition is reached. This time may consist of a period of lost identity and personal disorientation. (c) As the person gradually puts himself back together, he encounters the need to tell or conceal. (d) While the process of disclosure continues for the length of the disease, the person will stabilize his acceptance and begin the process of integrating this condition into a selfconcept. (e) As the person incorporates this information into a positive self-image, they may be able to face other secrets (p. 76-77).

The author stated, "critical elements for facilitating disclosure . . . include developing a trusting relationship with the client .... The nurse may facilitate disclosure by acknowledging cues and gently exploring them by inquiring about specific possible stigmatizing conditions" (p. 77).

Admi (1995) performed a study to explore the process of managing disease-related information through various developmental stages from the perspective of adults with cystic fibrosis. The sample included a total of 21 informants (ten individuals with cystic fibrosis and eleven of their closest relatives). During the initial phase of the study, a nonprobability purposive sampling technique was used to obtain a typical sample of the entire population with cystic fibrosis that was treated at a cystic fibrosis center. Further sampling was based on a theoretical sampling technique controlled by the analysis process. The interview guide included questions such as: "Can you recall the first time that you told someone about your cystic fibrosis?" and "What kind of reactions do you 
remember them having?" (p. 488). The constant comparative method of analysis was used to generate descriptive theory systematically. The basic social process of managing potentially stigmatizing information about the chronic disease was found to be a complex and dynamic process. Three categories of telling emerged as central to the processes of managing disease-related information among people with cystic fibrosis. These categories consisted of the following: (a) the choice of audience, (b) the choice of situation, and (c) the choice of telling strategy. The author summarized "data from this study suggest that situational and temporal factors such as timing, relevance, mood, others' interest, and a combination of these, influence the process of managing information about a chronic disease" (p. 493). Self-disclosure was found to serve as a means of relief, of self-definition through others, and seemed to contribute to the closeness and commitment of relationships.

\section{Conclusion}

A review of the literature revealed studies involving HIV/AIDS self-disclosure and general self-disclosure studies that suggested several factors were of vital concern when it came to self-disclosure of HIV-seropositivity or other stigmatizing conditions. These factors included fear of shame, fear of rejection/discrimination, and concern of privacy within the disclosure. This suggests that these factors were of concern regardless of the groups of individuals that were investigated. This clearly indicates a need for further investigation and clarification of self-disclosure processes of HIV-positive individuals and others, and to assist them by providing medical professionals with more information about the self-disclosure process. 


\section{CHAPTER 3}

\section{Method}

\section{Research Design}

The aim of phenomenological inquiry is to gain an understanding of an experience as if seeing the phenomenon for the first time. Phenomenological research is an inductive, descriptive approach, developed from phenomenological philosophy. It is a research method that tries to capture what other people and their lives are about without preconceiving the categories into which information will fit. Reality is always viewed as emerging and relative, rather than waiting to be located and measured. Therefore, the goal of phenomenological research is to describe an experience as it is lived by the person and to comprehend the meanings that the person places on this experience (Streubert \& Carpenter, 1995).

Phenomenological research examines particular experiences of unique individuals in a given situation. It is grounded in existential philosophy that embraces the idea that there is not a single reality, but that each individual has their own reality. It seeks to uncover meaning and essences in experiences so that understanding is facilitated, where an experience is considered unique to the individual. Phenomenology attempts to explore meaning within the realm of personal knowledge. It is an exploration of what reality is perceived to be. The findings of phenomenological research are descriptive with the purpose of enhancing nursing's knowledge base (Beck, 1994; Streubert \& Carpenter, 1995; Rose, Beeby, \& Parker, 1995). 


\section{Subject Recruitment}

Upon receiving approval from the University Research Council, the subjects were recruited from patients receiving health care services from the office of two private physicians who are HIV specialists. Participants met the following criteria:

1. Was a male age 18 years or older;

2. Had tested HIV-positive by the time the interview took place;

3. Had experienced a situation where self-disclosure of his HIV-positive status to a lover, friend, family member or health care worker took place;

4. Was alert and oriented;

5. Was willing to give informed consent.

Methods and Procedures

The principal investigator met with the physicians at their private office to review and explain the research objectives, purpose, methods and procedures. The principal investigator approached patients in the office during their regularly scheduled appointments. The purpose of the study was explained to the prospective participants of the study. Upon each person's expression of willingness to participate in this study, written informed consent was explained and signatures were obtained.

One interview was conducted with each participant and lasted approximately one hour. The individual interviews were conducted at pre-arranged dates, times, and locations convenient to the participant. Eighteen participants chose to have the interview conducted in a private room at the physicians' office and one participant chose to have 
the interview take place in his home. The interviews were audio taped after receiving written informed consent from each participant.

The participants were informed that even after the interview began, they could refuse to answer any specific clarifying questions, ask that the tape recorder be turned off at any time, or decide to terminate the interview at any point without affecting their participation in the study. Participants were informed that they could withdraw from the study at any time without any effect on the medical care they would receive from their physicians. The participants were also informed that should any emotional or psychological concerns arise as a result of their participation in this study, a referral to a psychiatrist or psychologist would be made by their physician. The interviews ended when the participants felt they had exhausted their descriptions of their experiences relating to disclosure of their HIV-seropositivity to another person. Data collection continued until repetition in the data occurred and the principal investigator found no new data were emerging.

Researcher's Personal Bracketing

Van Manen (1990) stated:

It is better to make explicit our understandings, beliefs, biases, assumptions, presuppositions, and theories. We try to come to terms with our assumptions, not in order to forget them again, but rather to hold them deliberately at bay and even to turn this knowledge against itself, as it were, thereby exposing its shallow or concealing character (p. 47). 
In keeping within the phenomenological perspective, the researcher continually addressed her own experiences and feelings related to HIV/AIDS (Coward \& Lewis, 1993; Beck, 1994; Streubert \& Carpenter, 1995). These experiences were written in a journal prior to starting this research, and were updated throughout the research study. This process, known as bracketing, was explained in detail in Chapter 1. In order for the reader to obtain a clearer picture of the researcher's thoughts and beliefs, the following is a brief description of the journal contents.

In the researcher's experience, she had worked with HIV/AIDS patients in a hospital setting for nearly eight years. The first HIV/AIDS patient admitted from the emergency room was vividly remembered. He was completely covered with sheets and blankets and wore a mask that covered his nose and mouth. The researcher remembered the frightened look in his eyes. He was placed in a room by himself at the farthest end of the hall. The door was kept closed, large orange isolation signs were posted everywhere outside his room, and a yellow isolation cart remained next to his door. The nurse that took care of him that day wore a surgical cap, goggles, mask, gown, double gloves and paper booties over her nursing shoes.

Over the years, things have changed dramatically in the care of HIV/AIDS patients. But the one thing that seemed to change the slowest was the number of patients that continued to suffer and die alone, all because they were afraid to tell loved ones that they had HIV/AIDS. Nurses on this AIDS unit suffered in silence, feeling totally helpless as to how to offer support to these individuals. They bought cakes and gifts to celebrate birthdays and Christmas, and most of all, they tried to be there with them when their time 
of passing became imminent. The nurses had a silent pact to try to never let any of the patients die alone.

Usually the patients would swear the nurses to secrecy, to not tell any visitors (if they had any), why they were in the hospital. Many mothers and fathers saw their sons die and it is unknown, to this day, if they ever realized that it was due to AIDS. The nurses became the patients' brothers and sisters, best friends, and confidantes. The patients always asked the same questions -- should they tell their families, when should they tell them, and how should they tell.

These individuals looked to the nurses for answers. The nurses became their lifelines as they openly and freely held their hands and provided hugs. They could meet most all of their needs, but could not help them communicate with their families and loved ones. The nurses looked to their managers, to staff physicians and psychiatrists, to research journals, and found no one or nothing available to help them. Today things are changing for the better. These HIV/AIDS individuals are finding more support and assistance in helping them tell of their HIV status. But there is still a need to provide self-disclosure information to those nurses who continue to care for these patients. HIV/AIDS may wear a new face today, but the same questions of who and how to tell still linger.

\section{Further Researcher Biases}

Normally, additional bracketing is not required in a research study unless something significant occurs that the researcher feels the need to bring out. However, about one week after the researcher had completed the interviews and had just begun transcribing them, she received a significant needlestick injury from one of "her" AIDS patients. She 
saw the drop of blood left at the tip of the needle as it entered deep into her finger, as if in slow motion. At that second, life as she knew it changed and has not been the same since. Other than the fear of infection, her other consuming thought was how to tell her husband that she might have become infected with HIV. She did tell him and has received his complete support.

The researcher also received immeasurable support from her coworkers and the physicians and immediately began a regimen of anti-viral medications. Suddenly she had gone from a nurse teaching her patients about medication side effects to becoming a patient, receiving the same information from her own physician. Having to set aside such personal feelings about possibly becoming infected with HIV has been difficult and has made this research study even more real, as a more personal understanding of what these men have lived and shared evolves.

\section{Data Analysis}

The data were analyzed using two approaches, that of Colaizzi (1978) and of Van Manen (1990). First the researcher chose to analyze the data by using Colaizzi's methodology. The researcher became the tool for data collection and listened to individual descriptions of the lived experience of HIV-seropositivity self-disclosure through the interview process. The interviews were then transcribed by the researcher to facilitate contemplation of the data. Data analysis required the researcher to become deeply immersed in the data and to commit fully to understanding what the data said. This required "... the researcher to be attentive to the subject's nuances of speech and 
gestures ..." (Colaizzi, 1978, p. 62). Colaizzi also felt the researcher must listen to the participants with more than just their ears;

... he must listen with the totality of his being and with the entirety of his personality. One can be present to the totality of a person only by being totally present to him; one must be present in every imaginable way; the researcher must assume the stance of imaginative listening (p. 64).

Colaizzi's approach included the following steps:

1) Read all of the subject's interviews in order to acquire a feeling for them. 2) Returned to each interview and extracted from them phrases or sentences that directly pertained to the investigated phenomenon. This was known as extracting significant statements. 3) Formulated meanings were obtained from these significant statements. 4) Meanings were clustered into themes. 5) The results were integrated into an exhaustive description of the investigated topic. 6) An effort was made to formulate the exhaustive description of the investigated phenomenon in as unequivocal a statement of identification of its fundamental structure as possible. 7) A final validating step was achieved by returning to each subject . . . asking the subject about the findings thus far. . . and incorporating any relevant new data that emerged. (Colaizzi, 1978, p. 59-61).

Due to the unexpected richness of the data obtained when using Colaizzi's (1978) approach, the researcher felt that further phenomenological exploration into the lived worlds as experienced by these men was warranted. Therefore, the researcher reflected on the data using the approach by Van Manen (1990) to further illuminate the findings. 
Van Manen described phenomenological research as the study of the lifeworld. He stated, "Phenomenology aims at gaining a deeper understanding of the nature or meaning of our everyday experiences. Phenomenology asks, 'What is this or that kind of experience like?"' (p. 9). Phenomenology presents an opportunity for an awareness that can bring a communion with our human-ness. Consequently, a goal of phenomenological research is to become more fully who we are and how we become more human. Van Manen stated, "The point of phenomenological research is to 'borrow' other people's experiences and their reflections on their experiences in order to better be able to come to an understanding of the deeper meaning or significance of an aspect of human experience, in the context of the whole human experience" (p. 62).

Van Manen (1990) identified fundamental existential themes known as lifeworld existentials, that he felt pervaded the lifeworlds of every person despite historical, cultural or social backgrounds. As examples, he spoke of the lifeworld of children, adults, men, women, teachers, parents, students, work, and home. These lifeworld existentials provided the guide for reflection on the data obtained thus far and are known as spatiality, temporality, relationality, and corporeality. In analyzing the data, the researcher felt the lifeworld existential known as corporeality or lived body was already present in the other three existentials and could not be extracted from the data in a meaningful way; therefore, only the lifeworld existentials of spatiality, temporality, and relationality were utilized. These lifeworld existentials are described in further detail in the following paragraphs. 
The first of these lifeworld existentials was known as lived space or spatiality. Van Manen (1990) stated that lived space is difficult to put into words since we ordinarily do not reflect on the experience of lived space. He stated, "In general, we may say that we become the space we are in" (p. 102). Van Manen felt that people have their own certain spaces in which they feel safety or comfort, as well as those spaces that make us feel exposed, vulnerable, or even excited. The second lifeworld existential was called lived time or temporality. Van Manen stated that lived time is subjective time, it is our "temporal way of being in the world. ... The temporal dimensions of past, present, and future constitute the horizons of a person's temporal landscape" (p. 104). The third lifeworld existential was lived other or relationality. Van Manen defined relationality as "the lived relation we maintain with others in the interpersonal space that we share with them" (p. 104). He felt that all of the existentials can be differentiated but not separated. They all come together to form an intricate web that we know as our "lived worlds". Van Manen (1990) described the essence of a phenomenon as:

... a universal which can be described through a study of the structure that governs the instances or particular manifestations of the essence of that phenomenon. In other words, phenomenology is the systematic attempt to uncover and describe the structures, the internal meaning structures, of lived experience. A universal or essence may only be intuited or grasped through a study of the particulars or instances as they are encountered in lived experience. .. The essence or nature of an experience has been adequately described in language if the description reawakens or 
shows us the lived quality and significance of the experience in a fuller or deeper manner (p. 10).

\section{Phenomenological Reliability and Validity}

Lincoln \& Guba (1985) developed four major criteria to establish trustworthiness of results from qualitative research: truth value, applicability, consistency, and neutrality. Truth value refers to the confidence one can have in the accuracy of the findings. To help ensure the credibility of this study, the researcher identified her presuppositions and bracketed them before data collection and analysis. The researcher returned to the study participants and asked that they review the data analysis. All of the participants agreed with the soundness of the findings and no modifications were required.

Applicability refers to the extent to which the findings apply outside of the study situation. Studies such as this one, show a more human side of HIV/AIDS. This disease is more than numbers and percentages; it affects the lives of men, women and children around the world. Medical administrators and professionals need to understand that HIV/AIDS care is unlike any other specialty. It is not medical, surgical, oncology, progressive or intensive care, but a unique combination of all of these specialties. Nurses still find the time to be compassionate, to listen and to care. But nurses also need to continue to follow new research and try new approaches to care. Nurses need to feel comfortable with sexual identities and sexual lifestyles that may be different than their own. Nurses need to become involved in easing the process of telling through knowledge of the conflicts that face these individuals. Lastly, nurses need to continue teaching their 
patients information regarding HIV transmission, safe sex practices, intravenous drug use, unplanned pregnancies, and other sexually transmitted diseases.

Consistency refers to the stability of the findings over time. Neutrality refers to the objectivity of the data. Both consistency and neutrality were achieved by using an audit trail. The thesis committee members followed the audit trail the researcher used to analyze the data, beginning with the interview transcriptions and ending with the exhaustive descriptions and essences. The real tests of reliability and validity are in the hands of readers who have personal or professional experience of the phenomenon of self-disclosure (Streubert \& Carpenter, 1995). 


\section{CHAPTER 4}

\section{Results}

Analysis of the nineteen interview transcriptions yielded 245 significant statements related to HIV-seropositivity self-disclosure to another person. Data was analyzed by first using the approach by Colaizzi (1978) (see Figure 1) and then by using Van Manen's (1990) approach (see Figure 2). This chapter reveals the findings obtained by this researcher using these two approaches.

\section{Demographic Data}

The age range (see Table 1) of the study participants consisted of the youngest participant being 34 years old, and the oldest participant being 65 years old. Fourteen of the participants had never been married, five were divorced, none were currently married. Three of the participants have children, sixteen have no children. Twelve of the participants currently live with a male partner, seven participants live alone, none of the participants live with a female partner.

\section{Data Analysis Using Colaizzi's Approach}

As the researcher dwelled with the interview data, significant statements were extracted. From these significant statements, patterns began to emerge and the researcher placed the statements under applicable formulated meanings. The formulated meanings became theme clusters from which exhaustive descriptions were developed. At the end of this process, the fundamental structure of self-disclosure was articulated in one sentence. The following paragraphs reveal the analysis of the findings. The four theme clusters are presented in the order of: price of honesty, telling, realization, and isolation. Examples of 
significant statements are given to demonstrate the richness of the data. Formulated meanings and theme clusters are identified next and are followed by their exhaustive descriptions.

\section{Theme 1}

Significant statements.

"He never called back again after that."

"I've received only good support from people."

"That's the way it is, especially with my mom. Um, that's difficult for me because I never had a relationship with my mother and I want one now and she doesn't want to be part of that ..."

“... people like my father, we still do not discuss it. He has known now I've been [HIV] positive for about ten years and he has known and we still do not even discuss it."

"When my dad actually found out, he quit speaking to me for two years, but he wouldn't discuss it, wouldn't talk about it. I didn't exist."

“... I got a lot more positive responses, you know, with people accepting it more and saying that it's no big deal."

"It's a level of support that once they're aware, that they can be there for you and just give you that little tiny bit of support that you need from a family person, parent or sibling."

"I know for a fact that my parents love me a lot."

Formulated meanings.

These significant statements, as well as others, were collapsed into two formulated meanings: abandonment and reinforcement. 
Table 1

Demographic Data of Male Study Participants

\begin{tabular}{cccc}
\hline AGE & $\begin{array}{c}\text { MARITAL } \\
\text { STATUS }\end{array}$ & CHILDREN & $\begin{array}{c}\text { LIVING } \\
\text { ARRANGEMENT }\end{array}$ \\
\hline 19 male participants & 14 never married & 3 have children & 12 with male partner \\
age range: & 5 divorced & 16 have no children & 7 live alone \\
oldest -65 years & 0 currently married & & 0 with female partner \\
youngest -34 years & & & \\
& & & \\
& & \\
\end{tabular}


Vigure I

Data Analysis Using Colaizzi's Approach

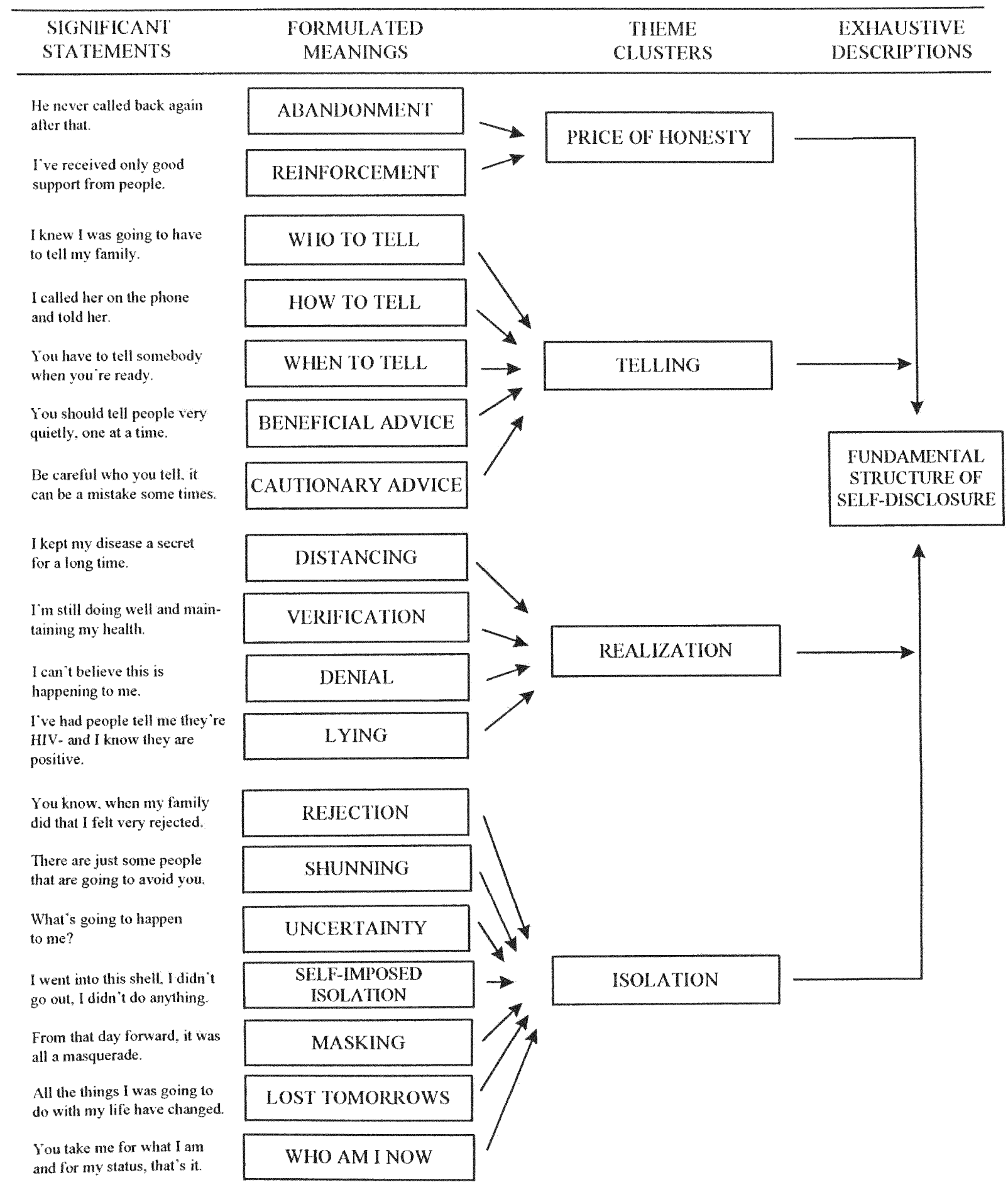


Theme clusters.

These formulated meanings were synthesized into the theme of Price of Honesty.

Exhaustive description.

Participants felt that the price of honesty resulted in feeling either abandonment or reinforcement. Some men stated actual incidents where after the HIV-positive disclosure took place, their lovers, family, or friends never spoke to them again. These men reported that sometimes this negative reaction would result in their reluctance to disclose their HIV status to another person for periods of time ranging from several months to several years. On the other hand, some of the men experienced very positive and supportive reactions from their lovers, family, or friends. This brought about a renewed sense of love, unity and concern from those persons closest to them. Most of the men agreed that no matter what the result might be, they always felt that honesty was the best policy.

\section{Theme 2}

Significant statements.

"I knew I was going to have to tell my family."

"I called her on the phone and told her."

"You have to tell somebody when you're ready."

"You should tell people very quietly, one at a time."

"Be careful who you tell, it can be a mistake sometimes."

"... I think if you have a close relationship with your family, they should be the first to know, unless you have a lover." 
“... I had to do it [tell my family] via telephone ... that wasn't very fair to do that over the telephone. I feel that this is an issue that should be confronted face to face as opposed to telephone."

"You have to tell somebody when you're ready to tell somebody and when you think that they're ready to hear it."

"There is no rush, you don't have to rush on anything like this. . . just give yourself a chance to adjust to it, what it means to you. .."

"I think you should tell. I think it helps relieve anxiety and stress from within yourself. I think it helps me to tell people instead of trying to harbor a secret."

"I just come right out and say it [that I'm HIV positive]. It's a mistake, a lot of times."

". . be cautious of who you tell in the beginning, because it can be devastating."

"[Another friend] who worked in ICU ... was very supportive, she called me at home, told me the same thing. . ' do not tell anybody' . . I I think you should lay very low, not tell anybody anything."

"Dr. D. even said to me 'I don't think you ought to let them [your friends] be involved in what's going on with you'."

Formulated meanings.

These significant statements, as well as others, were collapsed into five formulated meanings: who to tell, how to tell, when to tell, beneficial advice, and cautionary advice.

Theme clusters.

These formulated meanings were synthesized into the theme of Telling. Exhaustive description.

Participants shared their thoughts about the actual telling experience which included both beneficial and cautionary advice regarding who, how, and when to tell. 
Most of the men stated that after first telling their lovers of their HIV status, family members were the next to be told. How to tell about their status included telling faceto-face, by letter, and lastly, by telephone, which they felt was the most difficult. Also, most of the men agreed that as soon as possible after a relationship began, and even sometimes before a relationship began, was the best time to tell. The right time seemed to be the most important consideration involving when to tell. Beneficial advice that was given by some of the participants included taking it slow and to not rush into telling just anybody. Keeping a positive attitude about having HIV and not keeping it secret for a long period of time were also mentioned. Some of the men stated that it took more stress and energy to not tell someone of their HIV status than the stress that was initially encountered prior to the telling. Regarding cautionary advice, a few of the men felt that it had been a mistake when they had told someone of their positive status. One participant told of two separate instances where two of his doctors strongly advised him against telling anyone else of his seropositivity; therefore, he waited almost eight years before telling family and friends.

\section{Theme 3}

\section{Significant statements.}

"I kept my disease a secret for a long time."

"I'm still doing well and maintaining my health."

"I can't believe this is happening to me."

"I've had people tell me they're HIV-negative and I know they're positive." 
“... and he's [a good friend] having a real problem with, his boyfriend is telling everybody [that he's HIV positive]. He's going around telling people and we can't handle it. ...We need this one thing to keep our grip on and nobody lets us. It's like, it's like we've lost control of everything."

"We feel we have no value to society."

"... I've lived with incurable diseases all my life. But none of them was ever a source of shame and so I was the first one in my family to have a disease that was a social disgrace."

“. . I'm never going to meet anybody because I'm HIV positive."

"And so I kind of kept my distance . . . so I wouldn't contaminate them."

“... I can't believe this is happening to me."

"... and now everybody is saying 'oh it's a manageable disease, I can have unsafe sex' and it's going on everywhere. ... if you have sex with someone casually, you have to force them to have safe sex. It is very rare to meet someone who initiates safe sex and it's very disturbing. I mean, I would love to be able to trade places with one of these people. They don't know what they're talking about! They don't have a clue! They think that it's manageable? They don't want to live this way!"

". . I I thought okay, well, maybe I'll just have safe sex and I won't say anything."

"I've had people lie to me that they're not HIV-positive ..."

"I know people who won't tell anybody, who have unprotected sex. They don't care ..."

"I don't see any point of it [telling someone I'm HIV-positive] . . I mean, what are you gonna accomplish by telling somebody, you know ..."

Formulated meanings.

These significant statements, as well as others, were collapsed into four formulated meanings: distancing, verification, denial, and lying. 
Theme clusters.

These formulated meanings were synthesized into the theme of Realization.

Exhaustive description.

Participants described the reality of their lives having HIV and their selfdisclosures of HIV-seropositivity in several different ways. Distancing themselves, feeling isolated, or putting up protective barriers to keep themselves from the pain of self-disclosure were predominant thoughts that were brought out. The participants stated that the separation they felt between themselves and the rest of society was something very real to them, something that contained substance and texture. They used words such as uncomfortable, not understanding, overwhelming, loss of control, ashamed, embarrassed, and contaminated to describe the reality of their lives. Some men denied their HIV status for several years. One man stated that he didn't want to say it [the words "I am HIV positive"], so that it remained fiction rather than fact. Most of the men went through some phase of detachment from the truth because they just could not believe that they had contracted the HIV disease. Other men dealt with their reality by lying about their HIV status. Some of these men, when asked about their status, stated that they were HIV-negative. Others lied by omission, not even bringing the issue up, even when sexual encounters took place. One man stated that he didn't see any point of telling, feeling that nothing would be accomplished by telling a sexual partner of his HIV-seropositivity. 


\section{Theme 4}

Significant statements.

"You know, when my family did that I felt very rejected."

"There are just some people that are going to avoid you."

"What's going to happen to me?"

"I went into this shell, I didn't go out, I didn't do anything."

"From that day forward, it was all a masquerade."

"All the things I was going to do with my life have changed."

"You take me for what I am and for my status, that's it."

"... when the doctor gave me my bill ... he wrote HIV positive across the bill and he threw it at me across his desk..."

". . . coming out of the heart attack is when I found out that I was HIV. It was 'oh yeah, and by the way, you have AIDS and you're gonna die'. That's how I found out."

“. . it's still rejection and I don't care what anyone says, as long as you have AIDS, you look at it as rejection because of that."

"I've really never discussed with them ... I think ... that people would automatically ... shun away from me."

". . you just have to realize that there are some people that are going to avoid you."

"Don't look at me, don't even say my name..."

“. . . as far as being HIV-positive, it can be sometimes really difficult . . the uncertainty of it ..."

". . . you have this, this death in your mind all the time. That's what I did. I thought about it every day. 'I'm going to die'."

"Before it was a death sentence. I don't think it is today. The people that figured, 'well, I'm dying, so I'll do what I want', were wrong, you know. They always told 
them something was gonna come up tomorrow, wait for tomorrow . . You know, it has, it really has."

". . . it made me go into a shell and I didn't want to tell anybody. And, in fact, I didn't go out. I didn't do anything. I just stayed home ..."

"... I kind of like stayed reclusive for like three years ... I didn't have much to do with anyone. I kind of stayed by myself . .."

"I remember she [my doctor] told me I was going to have to put on the biggest front of my life, that I've ever done in my whole life. And I did. But from that day forward, on, it was all a masquerade."

"It still is very difficult for me to . . I still am afraid to meet other people because I don't want to be, you know, someone else to come in and tell me or tell somebody else that they saw [me] here, and did you know he has HIV ..."

“. . you know all the things I had planned to do. Things I was going to do with my life ... All those things have changed. . . your vision of what you can do, and your horizons are so limited, um, you just don't know what to plan for."

"I don't know what living without it [HIV] is anymore because it's been so long."

“... I'm still the same person, always have been."

". . . when I found out [he] was HIV-positive, you know, I didn't care if I was or not, cause I wanted, if he died, I wanted to die, you know, that was just the relationship."

“. . . even today I say I'm gay, I'm an alcoholic, and I'm HIV-positive. This is me, you know. If you can handle it, fine, if you can't, you know, you go your way and I'll go mine."

"... I thought, you know, how could you want to have anything to do with me. I'm like used waste material ..."

Formulated meanings.

These significant statements, as well as others, were collapsed into seven formulated meanings: rejection, shunning, uncertainty, self-imposed isolation, masking, lost tomorrows, and who am I now. 
Theme clusters.

These formulated meanings were synthesized into the theme of Isolation.

Exhaustive description.

Fear of rejection was an extremely powerful emotion that was tied to HIV selfdisclosure. Some men spoke of the rejection that was felt when they were initially diagnosed HIV-positive. The insensitive manner in which physicians told the men of their positive status left extremely negative impressions, which in turn, escalated their fears. Many men went to great lengths to avoid rejection, but it was the one thing that all of the participants stated that they had experienced at one time or another.

Regarding the issue of shunning, many men found themselves avoiding people in an effort to keep people from avoiding them first. Isolation was brought about by the uncertainty of the HIV disease and had several men confused about their futures. The thought that HIV led to AIDS which led to suffering and death is no longer necessarily true. Men who have had HIV for over fifteen years are still finding themselves healthy and very unsure of how to handle future plans. The fact that HIVpositive individuals are living longer and healthier lives may have an impact on the increased number of disclosures.

Some men were so traumatized by incidents relating to their HIV self-disclosures that they actually physically tried to withdraw from society. The men found themselves hiding out in their homes with little or no contact with the outside world. Others dealt with their HIV-positivity by hiding it from others. This differs from the previous self-imposed withdrawal by participating in society, but mentally hiding out, 
pretending to be something or someone that they were not. Some men felt the isolation more profoundly by realizing a loss of a future, of being unable to live long enough to pursue dreams and ambitions that they had. The men felt great difficulty in living in the present when there seemed to be no future for them.

In dealing with the isolation issue, men described feelings of being a different person than they had been, yet all the while struggling to remain the same. The element of who am I now also brought about opposing thoughts. Some expressed newly found strength and courage they previously had not known they possessed. Others felt the change in a more negative light, to the point where they felt they would never be a valuable or worthwhile person again. A profound statement made by one of the participants summed up the entire HIV self-disclosure issue to the fact that by disclosing one's HIV-positive status, you're also disclosing the fact that you're gay and promiscuous. In telling one thing, you've told them everything.

\section{Fundamental Structure of Self-Disclosure}

The four themes were blended into the following statement of identification: Isolation became the greatest reality when telling one's HIV-seropositivity, which was felt to demand a very high price.

\section{Summary}

This concluded the first analysis of the data performed by the researcher. The findings revealed an abundance of rich data. From this data four themes, their exhaustive descriptions, and a statement of the fundamental structure of self-disclosure, were developed. The themes price of honesty, telling, realization, and isolation were gleaned 
from the data and were used to preserve the spirit of the participants. Actual quotations from the participants were used to illuminate the full meaning of HIV-seropositivity selfdisclosure. Validation of the fundamental structure was essentially agreed upon by eleven of the nineteen participants.

\section{Data Analysis Using Van Manen's Approach}

Data analysis continued using three of Van Manen's (1990) lifeworld existentials of spatiality, temporality, and relationality. These three existentials were applied to the formulated meanings that had initially emerged from Colaizzi's approach, but the focus became even deeper and richer (see Figure 2). Building upon the data obtained so far, further analysis continued and included actual quotes from the participants, along with the researcher's interpretation of the essences as they pertained to the lived experience of HIV-seropositivity self-disclosure to another person.

Spatiality (lived space)

“. . lived space is a category for inquiring into the ways we experience the affairs of our day to day existence; in addition it helps us uncover more fundamental meaning dimensions of lived life" (Van Manen, 1990, p. 103). The formulated meanings that the researcher felt applied to spatiality are: abandonment, how to tell, distancing, rejection, and shunning. Examples of each are given below, followed by their corresponding essences.

\section{Abandonment.}

"I was honest and told him and he never called back."

"My father found out and he never spoke to me again." 
Figure 2

Data Analysis Using Van Manen's Approach

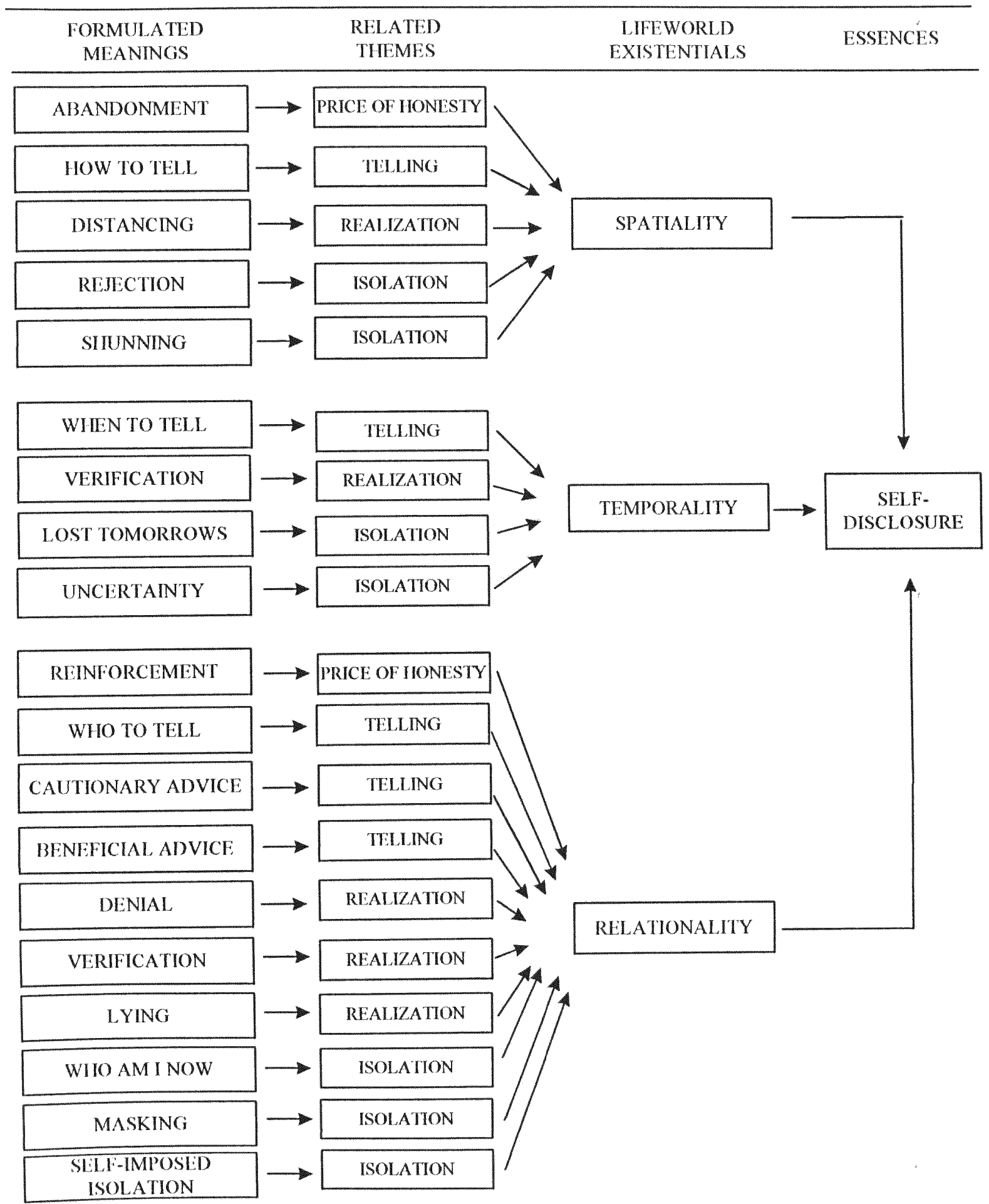


"A guy that I was dating was fine until he found out -.- then he freaked. . . he went his way, I went mine."

"People don't care. People who really care about each other try to nurture their relationship --- not abandon it."

"The fact is, some people take it well and some you never see again."

"From one rejection, the pain was so powerful it made me feel guilty, worthless, and infected. It's like being cut open, right here in the heart."

"Two relationships ended ... one day they were here ... the next day they were gone, no explanation, nothing."

"When I told a good friend, he stopped speaking to me."

Essence of Abandonment.

I told. Now they are gone...

How to Tell.

“. . I had to do it via telephone ... that wasn't very fair to do that over the phone. I feel that this is an issue that should be confronted face-to-face . .."

"I wrote her a letter and ... I got no response whatsoever, no phone call, no letter, nothing."

\section{Essence of How to Tell.}

Saying the words "I'm infected", how do I do that?

\section{Distancing.}

“... I can understand that my children are ashamed and embarrassed that I'm gay... .They are straight, they don't understand it. I can understand that my parents are ashamed and embarrassed because it is not acceptable to have a gay son."

"... his boyfriend is telling everybody. He's going around telling people and we can't handle it. We're not ready for that. We need this one thing to keep our grip on and nobody lets us. It's like, it's like we've lost control of everything."

"We feel like we have no value to society." 


\section{Essence of Distancing.}

I am a pariah if I tell. I remain in society only if I don't tell.

\section{Rejection.}

"I don't think they're bad, but it's still rejection and I don't care what anyone says, as long as you have AIDS [or HIV], you look at it as rejection because of that. You're never the same again. You can never be the same again. You feel damaged and devalued and worthless to the society you live in ..."

" . . I I had already called her [my sister] and told her . . that I was HIV positive. And she went nuts . . . she was afraid to touch me ... we'd cry and she didn't want to touch my tears ... and so I kind of kept my distance ... . so that I wouldn't contaminate them."

\section{Essence of Rejection.}

I've had so many people that I've loved turn away from me. Are they so afraid that I would purposely contaminate them?

\section{Shunning.}

"... you have to realize that there are some people that are going to avoid you."

'I'm so leery of nice people, it's terrible. ... And it's because I'm sure that they're going to judge me for something that I did, that I didn't know I was doing, and I didn't..."

\section{Essence of Shunning.}

Those I might have known, elude me. Nice people judge others. They won't even take the chance to know me.

\section{Temporality (lived time)}

"Lived time is also our temporal way of being in the world... Whatever I have encountered in my past now sticks to me as memories or as ... forgotten experiences that somehow leave their traces on my being ..." (Van Manen, 1990, p. 104). The 
formulated meanings that the researcher felt applied to temporality are: when to tell, verification, lost tomorrows, and uncertainty. Examples are given below, followed by their corresponding essences.

When to Tell.

"... I decided that I was going to tell him because I felt it was getting a little more involved now ..."

"You have to tell somebody when you're ready to tell somebody and when you think that they're ready to hear it."

“ . . if someone asks I will tell them, but I don't generally volunteer the information."

". . . I had made the choice that I was going to tell the individual that I was HIV positive. Only because I thought it was only fair especially if we were going to continue in the relationship..."

“... it's only going to make the relationship stronger if you tell the person in the beginning ..."

Essence of When to Tell.

When I tell them, how will it affect my relationships?

Verification.

"I can't believe this. It's been this long and I'm doing good ..."

"I've learned how to listen to my body and take care of myself and still enjoy life."

"... I learned a lesson that it's okay to have a good mental attitude about this, about having HIV in my life and it's okay, I'm going to make it."

Essence of Verification.

Maintaining my very being has become a process that never ends. I have to keep going inside myself and saying to myself that this is not the end of my life. This is my true strength. I can do this. 


\section{Lost Tomorrows.}

"... you know all the things I had planned to do. Things I was going to do with my life. .. . I wanted to go back to school . . buy a house . . . all those things have changed. You can't, your vision of what you can do, and your horizons are so limited, you just don't know what to plan for."

\section{Essence of Lost Tomorrows.}

There is no longer a dream of tomorrow. All that I could have been is gone.

\section{Uncertainty.}

"I was out with a group of friends and I turned to a person there and we started talking ... and during half way through the conversation and stuff, it came up whether I was HIV positive or not. And so I thought, should I tell him now, cause if I do, I feel like he's not going to talk to me any more. Or should I, you know, tell the truth. So I decided to tell the truth cause it didn't matter one way or the other."

\section{Essence of Uncertainty.}

How can I be sure that this is the right person, the right time to tell?

\section{Relationality (lived other)}

"... is the lived relation we maintain with others in the interpersonal space that we share with them. . . As we meet the other, we are able to develop a conversational relation which allows us to transcend our selves" (Van Manen, 1990, p. 104). The formulated meanings that the researcher felt applied to relationality are: reinforcement, who to tell, cautionary advice, beneficial advice, denial, verification, lying, who am I now, masking, and self-imposed isolation. Examples are given below, followed by their corresponding essences.

Reinforcement.

"My sister said she was behind me 100 percent." 
"It surprised me that my parents took it as well as they did."

"My brother will be there for me one of those days when I get sick."

"I told a good friend and she was wonderful. It was as if I were her own child."

"I think you need all the support you can get."

"I've gotten nothing but support from all of my family, friends, and coworkers."

"I was afraid to tell my father, but when he found out he said 'well, we're family, we'll get through this'."

"I have a very close circle of friends and all they show me is very positive loving concern."

\section{Essence of Reinforcement.}

I told. They care. They love me. To them, I'm still "me".

Who to Tell.

“. . I I said I have to tell somebody . . so I chose my sister . . ."

"I knew the rest of my family was going to have to know eventually, especially if I got sick."

“. . . I figured they [my parents] should be the first that I should tell that I'm HIV positive."

“... I think if you have a close relationship with your family, they should be the first to know, unless you have a lover."

"... I told my mother . . cause I felt she would be the easiest one to tell."

“. . . in order to get support from your family and friends, I feel that they have to know ..."

Essence of Who to Tell.

Who do I tell? How am I going to say the words? 


\section{Cautionary Advice.}

". . be cautious of who you tell in the beginning, because it can be devastating."

" ... just to be careful of who you tell. If people do act differently toward you, then they're not really your friends to start with."

"I just come right out and say it [that I'm HIV positive]. It's a mistake a lot of times."

" .. I I believe in safe sex. But I had two people that didn't care about having safe sex and I asked them why. And it was like they just felt like it didn't matter, you know. Which doesn't make sense to me cause you are HIV positive, no matter what level you're at or your health status. You realize there are serious consequences."

\section{Essence of Cautionary Advice.}

Don't trust anyone at first. Every person out there has the potential to hurt you.

\section{Beneficial Advice.}

“. . trust me, you will need the support of as many people as you can, especially in the beginning."

"I wouldn't waste time holding back, thinking that you don't want to tell them [your family]. Because, ah, you may just be amazed at their response. And had I known that I was so alone from the beginning, that I was going to get absolutely no financial help of any kind or any support of any kind, I would have reached out to friends a lot sooner. But I always thought well, you know, when it gets really bad, the family will be there. So I would say to people to go ahead and tell people and don't expect them to take it from your point of view."

"You should do that [tell people] very quietly, slowly. One at a time ..."

"I don't volunteer anything. If they ask questions, then I tell them."

"... I'd rather go ahead and be honest with people right from the beginning and let them know where I'm coming from and I find that in the long run, you will maintain sound quality relationships that way."

"I think with family, you just play it by ear. There is no rush, you don't have to rush on anything like this ... just give yourself a chance to adjust to it, what it means to you." 
". . just go slowly and just give them time to digest it."

\section{Essence of Beneficial Advice.}

Take your time, you'll know when they're ready . . . you'll know when you're ready...

\section{Denial.}

“. . . when I first found out . . . it was like devastating. I just couldn't tell anyone, you know, because I couldn't deal with it myself. And I had a really hard time to accept it, cause I thought, you know, I'd be the last person . . ."

"I put off making that appointment with the doctor for a month. Cause it was just denial on my part. I knew what they told, when they told me this, it was like shattering ... because you have all these plans and things for your life and all these things that we were going to do..."

" . . . and now everybody is saying 'oh, it's a manageable disease, I can have unsafe sex' and it's going on everywhere. .. If you have sex with someone casually, you have to force them to have safe sex. It is very rare to meet someone who initiates safe sex and it's very disturbing. I mean, I would love to be able to trade places with one of these people. They don't know what they are talking about! They don't have a clue! They think that it's manageable? They don't want to live this way!"

\section{Essence of Denial.}

I couldn't believe this had happened to me! I didn't know how to face it!

\section{Verification.}

". . . my favorite saying is 'I've found nothing negative about being positive' because I learned how to take care of myself. I'm healthier now than I was back then because I've learned how to listen to my body and take care of myself and still enjoy life."

\section{Essence of Verification.}

I have to believe that I'm living instead of dying. This helps me to maintain some semblance of normalcy. 
Lying.

"I've had people lie to me that they're not HIV positive. . . I told somebody that I was HIV positive and they told me they weren't and then I said you don't mind going out and then when we went out together on a date and fooled around, the next day they told me they were positive .. . I could never understand why they lied."

“. . I I just know, like there's several people that I see, if they ever knew, they would never come back again, I'd never see them or hear from them ..."

\section{Essence of Lying.}

One lies to live...

\section{Who Am I Now.}

"And then I would get to the point, thinking, you know, this is an illness, this is something that I shouldn't be ashamed to have to tell but it carries this, this ah . . . stigma with it. You're gay, you've got HIV, and you got it from being promiscuous . . I mean, you tell them one thing, you're telling them everything else."

\section{Essence of Who Am I Now.}

Tell ... and you tell all ...

\section{Masking.}

"I remember she [my doctor] told me I was going to have to put on the biggest front of my life, that I've ever done in my whole life. And I did. From that day forward on, it was all a masquerade."

“. . I I hear what they tell me, but I want to tell them 'if you only knew I was HIV positive and I'm living'. But I don't want to scare them off. I want them to know me as a human being instead of me as being HIV positive ... I don't want them to see this dark cloud that hangs over me."

\section{Essence of Masking.}

I hid my true self from the world, for who would want to know what I have become? 


\section{Self-imposed Isolation.}

"... I was trying to find, you know, how to cope, to express myself and how to reach out to people, you know, what to say and what to do. And then I found out, it was like the rug was jerked out from under me, and I kind of went into a deep depression and just cut myself off from the world..."

\section{Essence of Self-imposed Isolation.}

I found a place where I could be safe, where no one could hurt me.

\section{Summary}

After first having analyzed the data using Colaizzi's (1978) methodology, further analysis was accomplished by using Van Manen's (1990) lifeworld existentials of spatiality, temporality, and relationality. These existentials were used to enhance the intensity and vividness of the formulated meanings that had initially been brought to light earlier in the study by Colaizzi's approach. From the participant's quoted thoughts and feelings, essences were extracted to further illuminate the meaning of self-disclosure of HIV-seropositivity to another person. 


\section{CHAPTER 5}

\section{Discussion and Conclusion}

\section{Discussion}

The data discovered in this study speaks of greater meaning and depth of understanding to those individuals who are HIV-positive and considering self-disclosure. In this study, the theme of price of honesty revealed feelings of abandonment or reinforcement. Several of the previous studies (Katz, 1997; Simoni et al., 1995; Stempel et al., 1995; Mansergh et al., 1995; Moneyham et al., 1996; Admi, 1995; and Inhorn, 1986) revealed participants that had also either experienced positive and supportive feedback when telling someone of their HIV-positive status; or had experienced feelings of abandonment, which sometimes left the participants feeling confused and angry at loved ones. The participants in this study felt that being honest and disclosing their HIVseropositivity had, at times, exacted a high price (i.e. after the self-disclosure loved ones never spoke to them again), but that it was something that had to be done, and sometimes resulted in a renewed sense of love and unity. No matter the outcome, the study participants basically felt they had been right in disclosing their HIV-positive status to their lovers, families, and friends.

The theme of telling included advice regarding who, how, and when to tell of one's HIV status. Findings were similar to those found in studies by Marks et al. (1992), Schnell et al. (1992), Perry et al. (1994), Mansergh et al. (1995), Stempel et al. (1995), Simoni et al. (1995), Sobo, (1995), and Admi (1995). In this study, the participants suggested that lovers should be told before any other family or friends and suggested not 
keeping it secret for a long period of time. Participants discussed the amount of stress and energy wasted on worrying about their anticipated HIV disclosures. Different ways of how and when to tell were discussed, but the participants generally agreed that the individual had to be ready to tell about their HIV-positive status.

The theme of realization brought out feelings of denial, distancing, and lying (Sobo, 1995; Katz, 1997; and Limandri, 1989). Participants spoke of the distance they felt between themselves and the rest of society. Some participants felt an overwhelming disbelief that they had contracted the virus and were HIV-positive and dealt with this reality by lying about their status. Participants that had successfully dealt with their HIVseropositivity and had maintained a positive attitude described going through steps similar to those described by Limandri (1989).

The final theme of isolation uncovered feelings of rejection, shunning, uncertainty, self-imposed isolation, masking, lost tomorrows and who am I now. Simoni et al. (1995) found data that suggested that when HIV-positive individuals disclosed to their lovers, many of the lovers became angry and withdrew from the relationship. Moneyham et al. (1996) discovered that concerns regarding confidentiality impacted participants' use of resources, community services and health clinics. Limandri (1989) explained one of the steps of the self-disclosure process consisted of "lost identity and personal disorientation" (p.77). Participants in this study spoke of still being who they used to be (before contracting HIV), yet questioning who they were today. Some of the participants spoke of masquerading, either pretending to be something they were not, or pretending to be who they were before contracting HIV. Many of the participants spoke of future plans 
they had abandoned in anticipation of an early death, only to find themselves still alive and healthy, with no immediate demise in sight. Rejection, shunning, and withdrawing from society, were experienced by most of the participants at one point in time.

Data analysis obtained using Van Manen's (1990) methodology provided the researcher the opportunity to share the meaning of everyday experiences as they were described by these men. An attempt was made by the researcher to describe and interpret these meanings to a particular quality of depth and richness. The reader is reminded that these phenomenological descriptions are the interpretation of this researcher and "no single interpretation of human experience will ever exhaust the possibility of yet another complementary, or even potentially richer or deeper description" (Van Manen, 1990, p. 31).

\section{Conclusion and Expectations}

This study uncovered the complex nature of self-disclosure as the researcher dwelled with the interviews and as the data became meanings and as meanings became themes. The researcher felt the emotional bewilderment, the constant questioning of self, of "should I tell?" or "should I not tell?". These questions led to more questions, such as "what if I tell and he leaves me?" or "what will happen if I don't tell?". The constant litanies and dialogues with one's self, such as, "I need to tell him because I need his support"; "I'm strong, I can do this by myself"; or "no I can't, I need someone to hold me and tell me it'll be okay". These were some of the thoughts spoken by men who are dying to be heard. 
A major finding of this study came to light while contemplating data involving the theme of telling. This finding involved the aspect that self-disclosing one's HIVseropositivity is unlike any other type of self-disclosure. Specifically, for this male population, the disclosing of one's positive HIV status revealed the most personal and private facets of one's life. As one participant stated, “. . this is something that I shouldn't be ashamed to have to tell but it carries this, this, ah, stigma with it. You're gay, you've got HIV and you got it from being promiscuous ... I mean, you tell them one thing, you're telling them everything else ...".

This is indeed a unique dilemma faced by all HIV-positive individuals due to the negative stigma that still remains attached to HIV transmission and infection. The general population, for the most part, may still believe that acquiring HIV/AIDS is a punishment meted out to that segment of society consisting of homosexuals, intravenous drug users, and male and female prostitutes. Unfortunately, many of these may still be composed of nurses and physicians that also believe this fallacy.

By sharing the thoughts and feelings as related by these individuals regarding selfdisclosure, it is hoped that nurses who work with HIV-positive men and women will become more understanding and supportive to this particular concern. Self-disclosure of one's HIV-seropositivity to another person is still a critical and devastatingly emotional part of one's life to share with another. Nothing is nearly as difficult as saying to another person "I am HIV-positive". 


\section{Implications for Nursing Practice}

Studies such as this one, show a more human side of HIV/AIDS. This disease is more than numbers and percentages; it affects the lives of men, women and children around the world. Medical administrators and professionals need to understand that HIV/AIDS care is unlike any other specialty. It is not medical, surgical, oncology, progressive or intensive care, but a unique combination of all of these specialties. Nurses still find the time to be compassionate, to listen and to care. But nurses also need to continue to follow new research and try new approaches to care. Nurses need to feel comfortable with sexual identities and sexual lifestyles that may be different than their own. Nurses need to become involved in easing the process of telling through knowledge of the conflicts that face these individuals. Lastly, nurses need to become more knowledgeable regarding their patient's concerns about the impact of self-disclosure of HIV serostatus on primary relationships.

\section{Recommendations for Further Research}

More phenomenological studies are needed that look into the feelings of "telling all" when facing self-disclosure of HIV-seropositivity. Development of interventions for nurses, other medical professionals and the individuals themselves are greatly needed. As HIV becomes a chronic disease, individuals will need to learn how to re-enter and live in society again. 


\section{REFERENCES}

Admi, H. (1995). "Nothing to hide and nothing to advertise", Managing diseaserelated information. Western Journal of Nursing Research, 17(5), 484-501.

Beck, C. T. (1994). Phenomenology: Its use in nursing research. International Journal of Nursing Studies, 31 (6), 499-510.

Beck, C. T. (1994). Reliability and validity issues in phenomenological research. Western Journal of Nursing Research, 16(3), 254-267.

Colaizzi, P. F. (1978). Psychological research as the phenomenologist views it. In R. Valle \& M. King (Eds.), Existential phenomenological alternative for psychology (pp. 48-71). New York: Oxford University Press.

Coward, D. D. \& Lewis, F. M. (1993). The lived experience of self-transcendence in gay en with AIDS. Oncology Nursing Forum, 20(9), 1363-1368.

Derlega, V. J. (1988). Self-disclosure: Inside or outside the mainstream of social psychological research? Journal of Social Behavior and Personality, 3(2), 27-34.

Derlega, V. J., Metts, S., Petronio, S. \& Margulis, S. T. (1993). Self-disclosure. Newbury Park, CA: Sage Publications, Inc.

Doll, L. S., Harrison, J. S., Frey, R. L., McKirnan, D., Bartholow, B. N., Douglas, Jr., J. M., Joy, D., Bolan, G. \& Doetsch, J. (1994). Failure to disclose HIV risk among gay and bisexual men attending sexually transmitted disease clinics. American Journal of Preventative Medicine, 10(3), 125-129.

Fanning, M. M. (1997). HIV infection: A clinical approach (2 $2^{\text {nd }}$ ed.). Philadelphia, PA: W. B. Saunders Company. 
Fineberg, H. V. (1988). The social dimensions of AIDS. Scientific American, October, $128-134$.

Fisher, D. V. (1984). A conceptual analysis of self-disclosure. Journal for the Theory of Social Behavior, 14(3), 277-296.

Flaskerud, J. H. \& Ungvarski, P. J. (1995). HIV/AIDS: A guide to nursing care ( $3^{\text {rd }}$ ed.). Philadelphia, PA: W. B. Saunders Company.

Hoff, C. C., Stall, R., Paul, J., Acree, M., Daigle, D., Phillips, K., Kegeles, S., Jinich, S., Ekstrand, M. \& Coates, T. J. (1997). Differences in sexual behavior among HIV discordant and concordant gay men in primary relationships. Journal of Acquired Immune Deficiency Syndromes and Human Retrovirology, 14(1), 72-78.

Inhorn, M. C. (1986). Genital herpes: An ethnographic inquiry into being discreditable in American society. Medical Anthropology Quarterly, 17(3), 59-63.

Katz, A. (1997). 'Mom, I have something to tell you' - Disclosing HIV infection. Journal of Advanced Nursing, 25, 139-143.

Lincoln, Y. \& Guba, E. (1985). Naturalistic inquiry. Newbury Park, CA: Sage Publications.

Limandri, B. J. (1989). Disclosure of stigmatizing conditions: The discloser's perspective. Archives of Psychiatric Nursing, 3(2), 69-78.

Mansergh, G., Marks, G. \& Simoni, J. M. (1995). Self-disclosure of HIV infection among men who vary in time since seropositive diagnosis and symptomatic status. AIDS, 9(6), 639-644. 
Marks, G., Bundek, N. I., Richardson, J. L., Ruiz, M. S., Maldonado, N. \& Mason, H. R. C. (1992). Self-disclosure of HIV infection: Preliminary results from a sample of Hispanic men. Health Psychology, 11(5), 300-306.

Marks, G., Richardson, J. L. \& Maldonado, N. (1991). Self-disclosure of HIV infection to sexual partners. American Journal of Public Health, 81(10), 1321-1323.

Moneyham, L., Seals, B., Demi, A., Sowell, R., Cohen, L. \& Guillory, J. (1996). Experiences of disclosure in women infected with HIV. Health Care for Women International, 17, 209-221.

Mullins, I. L. (1996). Nurse caring behaviors for persons with Acquired Immunodeficiency Syndrome/Human Immunodeficiency Virus. Applied Nursing Research, 9(1), 18-23.

Munhall, P. L. (1994). Revisioning phenomenology: Nursing and health science research. New York, NY: National League for Nursing.

Perry, S. W., Card, C. A. L., Moffatt, Jr, M., Ashman, T., Fishman, B. \& Jacobsberg, L. B. (1994). Self-disclosure of HIV infection to sexual partners after repeated counseling. AIDS Education and Prevention, 6(5), 403-411.

Rose, P., Beeby, J. \& Parker, D. (1995). Academic rigour in the lived experience of researchers using phenomenological methods in nursing. Journal of Advanced Nursing, 21, $1123-1129$.

Schnell, D. J., Higgins, D. L., Wilson, R. M., Goldbaum, G., Cohn, D. L. \& Wolitski, R. J. (1992). Men's disclosure of HIV test results to male primary sex partners. American Journal of Public Health, 82(12), 1675-1676. 
Simoni, J. M., Mason, H. R. C., Marks, G., Ruiz, M. S., Reed, D. \& Richardson, J. L. (1995). Women's self-disclosure of HIV infection: Rates, reasons, and reactions. Journal of Consulting and Clinical Psychology, 63(3), 474-478.

Sobo, E. J. (1995). Human immunodeficiency virus seropositivity self-disclosure to sexual partners: A qualitative study. Holistic Nursing Practice, 10(1), 18-28.

Stempel, R. R., Moulton, J. M. \& Moss, A. R. (1995). Self-disclosure of HIV-1 antibody test results: The San Francisco General Hospital Cohort. AIDS Education and Prevention, 7(2), 116-123.

Streubert, H. J. \& Carpenter, D. R. (1995). Qualitative research in nursing: Advancing the humanistic imperative. Philadelphia, PA: J. B. Lippincott Company. Van Manen, M. (1990). Researching lived experience: Human science for an action sensitive pedagogy. Ontario, Canada: The State University of New York. 


\section{APPENDIX A}

\section{INFORMED CONSENT}

Project Title: A Phenomenological Study of Self-Disclosure of Male's HIV Seropositivity to Another Person

Elaine DiVeronica, R.N., a graduate student at Florida International University, is conducting this research study as part of her Master of Science in Nursing degree requirement.

1. PURPOSE: You are being asked to participate in a research study to help nurses understand what it means for an HIV-positive male to experience revealing their positive HIV status to another person, (i.e. partner, friend, family member, etc.). The feelings associated with self-disclosure need to be investigated and described so that health care providers can offer insight and guidance to those currently infected and to those who become HIV infected.

2. PROCEDURE: You will be interviewed at a time and place convenient to you. There will be one to two interviews, each lasting approximately one hour. The interviews will be audio taped and will be transcribed verbatim by the principal investigator. Even after the interview begins, you may refuse to answer any specific questions, ask that the tape recorder be turned off at any time, or decide to terminate the interview at any point without affecting your participation in the study.

3. RISKS: There are no anticipated risks associated with your participation in this study. However, should any emotional or psychological concerns arise as a result of your participation in this study, referral to a psychiatrist or a psychologist can be made by your on-site physician.

4. BENEFITS: Your participation will be of no direct benefit to you; however, HIVpositive individuals, now and in the future, may benefit from revealed feelings about HIV self-disclosure that may be discovered in this study.

5. CONFIDENTIALITY: Your participation in this study is confidential to the extent permitted by the law. The audio tapes will identify you by an assigned number known only to the principal investigator and faculty supervisor. The list of numbers assigned to each participant will remain in a separate locked box at the principal investigator's home. The audio tapes and the typewritten transcriptions will be kept in a locked file cabinet also located in the principal investigator's home. Once the study has been completed, you may elect to have your audio taped interview returned to you or have it destroyed by the principal investigator. You will not be identified by name in any presentation or publication of the data collected in this study. 
6. VOLUNTARY PARTICIPATION: Your participation in this research study is voluntary. There will be no negative consequences if you choose not to participate. You are free to withdraw from the study at any time.

7. QUESTIONS: If you have any further questions, you may contact Elaine DiVeronica at 954-429-8727 or 954-629-6658. You may also contact the Faculty Supervisor, Dr. Sandra Lobar, Florida International University, at 305-919-5915.

I have read, had explained to me, and understand this statement of Informed Consent. I have been given a copy of this consent form. I voluntarily agree to become a participant in this research study.

Participant's Signature Date

Principal Investigator's Signature

Date 


\section{APPENDIX B}

\section{RESEARCH PROTOCOL FOR IRB REVIEW}

\section{RESEARCH OBJECTIVE}

This study seeks to accomplish the following research objective:

To investigate, understand and describe what it means for an HIV-positive male to experience revealing their positive HIV status to another person so that health care providers can offer insight and guidance to those currently infected and to those who become HIV-infected.

\section{SUBJECT RECRUITMENT}

Upon approval from the University Research Council, the subjects will be recruited from patients receiving health care services from two private physicians who are HIV specialists. Participants should meet the following criteria:

1. Must be a male age 18 years or older;

2. Must have tested HIV-positive by the time the interview takes place;

3. Must have experienced a situation where self-disclosure of his HIV-positive status to a lover, friend, family member or health care worker took place;

4. Must be alert and oriented;

5. Must be willing to give informed consent.

\section{BENEFITS}

Findings from this study may help in identifying patient's feelings about disclosure of stigmatizing conditions, such as HIV/AIDS and will be of benefit to nurses and other 
health care providers in offering insight and guidance to those who are and who become HIV-positive.

\section{INFORMED CONSENT}

The informed consent will be obtained upon the voluntary agreement of each participant in this study (See Appendix A). The participant will be told that each audio taped interview should take about one hour to complete. The research purpose and procedures; the participant's experiences, benefits, risks; and confidentiality will be explained to each of the participants. The names and telephone numbers of the principal investigator and the faculty supervisor will be included on the form so that the participants may contact either individual for additional questions regarding this study. The participants will be told that all signed consent forms and typed interviews will be kept in a locked file cabinet for three years after the project terminates. The participants may elect to have their audio taped interviews returned to them or be destroyed by the principal investigator.

\section{CONFIDENTIALITY OF DATA}

Data confidentiality will be secured as follows:

1. audio-taped interviews will be transcribed only by the principal investigator;

2. each participant will be assigned a code number which will be used instead of their names;

3. a master list will be made to include each participant's name and their corresponding code number to ensure proper identification relevant to each participant; 
4. information obtained will be available only to the principal investigator, faculty supervisors, and members of the thesis committee;

5. findings will be reported using fictitious names and will in no way identify any participant of this study;

6. all research data will be kept separately from the master list of participant names, in a locked file cabinet by the principal investigator for a period of at least three years.

\section{METHODS AND PROCEDURES}

The study will be conducted in the following manner:

1. The principal investigator will meet with the physicians at their private office to review and explain the research objectives, purpose, methods and procedures.

2. The principal investigator will approach patients in the office during their regularly scheduled appointments. The purpose of the study will be explained to the prospective participants of the study. Upon each person's expression of willingness to participate in this study, the written informed consent will be explained and signatures obtained.

3. There will be one to two interviews with each participant, each interview lasting approximately one hour. Individual interviews will be conducted at a prearranged date, time and location convenient to the participant. The interviews will be audio taped after receiving informed consent from each participant. The participant will be informed that even after the interview begins, he can refuse to answer any specific clarifying questions, ask that the tape recorder be turned off 
at any time, or decide to terminate the interview at any point without affecting his participation in the study. The participant will also be informed that he may withdraw from the study at any time without any effect on the medical care he may receive from his physician.

4. The interviews will end when the participants feel they have exhausted their descriptions of their experiences relating to disclosure of their HIV-seropositivity to another person. Data collection will continue until repetition in the data occurs or the principal investigator finds that no new data are emerging, thus achieving saturation.

5. All consent forms and typed interviews will be secured by the principal investigator and stored in a locked file cabinet for a minimum of at least three years.

\section{STIMULUS MATERIALS}

Data collection will be achieved by audio taped interviews only. There will be no questionnaires or other stimulus materials used in this study.

\section{RISKS TO SUBJECTS}

There are no anticipated risks associated with participation in this study. This is a phenomenological study that does not involve any manipulation and allows for only voluntary participation. However, should any emotional or psychological concerns arise as a result of participation in this study, referral to a psychiatrist or a psychologist can be made by the participant's on-site physician. 


\section{APPENDIX C}

\section{IRB APPROVAL}

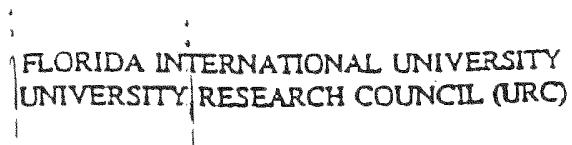

APPLICATION FOR APPROVAL OF RESEARCH INYOLVING HUMAN SÜBJECTS

1. PROJECT TITLE: A PHENOMENOLOdICAL STUDY OF SELF-DISCLOSURE OF HYV SEROPOSITIVITY TO ANOTHER PERSON

2. PRINCIPAL INVESTIGATOR: Elaine Diveronica SSH: $362-62-2447$

Address: 1416 S.W. 25th Ave Deerfield Beach, Phone "t: $954-429-8727$ FL

Position: [ ] Faculty [x] Graduale Student [ ] Undergraduare Studens [ ] Other (Specify)

3. FACULTY SUPERVISOR (if PI is a student): Dr. Sandra Lobar

4. STATUS OF PROJECT REVIEW:

$[x]$ New project [ ] Revision of previously approved project \& ] Continuation of approved project

5. BREF DESCRPTION OF SUBJECTS

Number of subjecss: $10-20$

Check all of the following categories that describe your research subjects:

$\left[_{\mathrm{x}}\right]$ Males

(1) Females

(1) Minors (under 18 years old)

( ) Studens (Please Specify):

[ ] Persons Wich Physical Disabiliues (Please Specify):

(1) Persons With Mental/Psychological Disabilities (Please Specify):

[XX] Persons With Physical or Mental Health Problems (Please Specify): HIV pos it ive

( ) Persons With No Known Disabilities and No Known Health Problems

( ) Prisoners

( ) Pregnant women, feruses, fetal material or placenus (Please Specify):

( ) Persons In Some Type of Program (Please Specify):

1 I Other Perrinent Information (Please Specify):

6. TYPE OF REVIEW REQUESTED (See pages 6 \& 7 of the Information for Experimenters bookles):

I I Exempr: Category H(s):

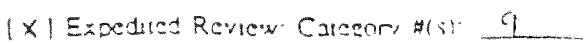




\section{$\because$ AFFIRMATION OF COMBLIANCE AND ACCEPTANCE OF RESPONSIBULTY}

I agree to follow the procelures outliled in this summity description and any aunchmenis. I understand that no contac: may be initiated with subjecse until I have rece:ved approval of these procedures from the URC and have complied with any modificitions required in conncetior. with that approval. I undersiand that additions to or changes in the procedures involving buman subjects $\approx$ f only be made after approval of the URC. I understand that I must promplly report to the Un $C$ any problems yith the rights or welfare of the human subjects. I

understand and will follow Florida Iniernational University's policies concening research with human subjects. I will do everything in my power to protes the rights and welfare of hurnan subjects in my researth projec:

A Phenomenological Study of Self-Disclosure of HIV Seropositivity To (print tille of project here) Another Person

Elane A. Diveronca

Signaure of Principal Investignwor

$\frac{10-28-56}{\text { Date }}$

Elaine A. Diveronica

Printed name of Principal Investigator

If the PI is a student. the faculty supervisor must sign below.

I have read this applicasion and assume repponsibility for its accuracy and for supervision of the proposed research project.

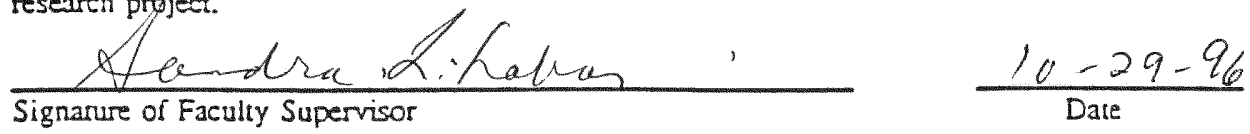

Dr. Sandra Lobar

Printed name of Faculty Supervisor

;

ACTION RECOMMENDED BY URC "For URC use only"

Date: $1 / / 10 / 90, M$ Approved I ] Changes/Clarifications Requested I I Require Full Soard Review

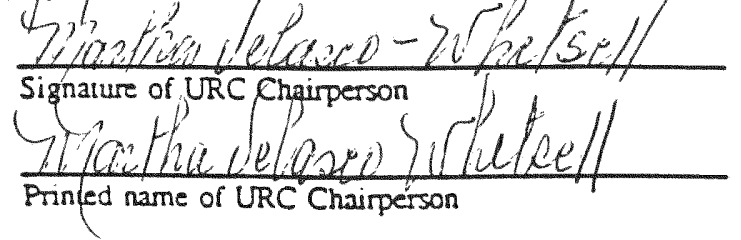

Date:

( 1 Approved

I ] ChangestClarificaions Requested.

( ) Require Full Board Review

Signature of URC Chairperson

Date: 